\title{
SEVERE SPONDYLOLISTHESIS IN CHILDREN AND ADOLESCENTS
}

\author{
A LONG-TERM REVIEW OF FUSION IN SITU \\ S. SEITSALO, K. ÖSTERMAN, H. HYVÄRINEN, D. SCHLENZKA, M. POUSSA
}

From the Orthopaedic Hospital of the Invalid Foundation, Helsinki

\begin{abstract}
From 1948 to 1980, 93 children and adolescents had fusion in situ for severe spondylolisthesis with a slip of $50 \%$ or more, at a mean age of 14.8 years. Of these, 52 girls and 35 boys were reviewed after a mean follow-up of 13.8 years. The mean pre-operative slip was $76 \%$ and pain frequency correlated with the severity of the lumbosacral kyphosis but not with that of the slip.

Posterior fusion was used in 54, posterolateral in 30 and anterior fusion in three patients. There were no major complications but 16 had re-operations for non-union or root symptoms. At follow-up there were three non-unions. After operation, 19 patients had $10 \%$ or more progression of the slip, but 10 showed correction by more than $10 \%$ as a result of remodelling. The lumbosacral kyphosis had increased by more than $10^{\circ}$ in 45\%. Postoperative progression of the slip and of lumbosacral kyphosis was significantly more if the posterior element had been removed. At follow-up 77 patients were subjectively improved, four were unchanged, and one was worse. These results did not correlate with either the degree of the slip, or the angle of lumbosacral kyphosis.

Fusion in situ is safe and gives good long-term clinical results. Secondary changes are associated with increased lumbosacral kyphosis, so reduction of this should be considered in severe cases.
\end{abstract}

In 1782, the Belgian gynaecologist Herbiniaux first described lumbosacral luxation and it was Rokitansky in 1839 , and Killian in 1854, who first used the term 'spondylolisthesis'. Since then, its aetiology and treatment have been extensively discussed, but opinions still differ on the treatment of severe slip. Posterior fusion in situ was suggested by Meyerding (1932) for severe cases, while Watkins (1953) and Wiltse (1961) preferred posterolateral fusion in situ. Jenkins (1936) was the first to report reduction of spondylolisthesis using longitudinal traction followed by anterior intercorporeal fusion, but the reduction could not be maintained. Newman and

\footnotetext{
S. Seitsalo. MD, Orthopaedic Surgeon

Jorvi Hospital, Espoo, Finland.

K. Österman, MD, Orthopaedic Surgeon, Assistant Chief

D. Schlenzka, MD, Orthopaedic Surgeon

M. Poussa, MD, Orthopaedic Surgeon

Orthopaedic Hospital of the Invalid Foundation, Tenholantie 10 Helsinki, Finland.

H. Hyvärinen, MD. General Surgeon

Second Department of Surgery, Helsinki University Central Hospital, Helsinki. Finland.

Correspondence should be sent to Dr S. Seitsalo.
}

(C) 1990 British Editorial Society of Bone and Joint Surgery $0301-620 X / 90 / 2042 \$ 2.00$

J Bone Joint Surg [Br] 1990; 72-B:259-65.
Stone (1963) warned of the risks of reduction, and recommended fusion in situ. The main arguments against this have been that cosmetically-disturbing deformity cannot be eliminated (Boxall et al 1979; Bradford 1979), that the rate of non-union after fusion in situ may be high (Turner and Bianco 1971; Boxall et al 1979), and that the tendency to progression remains in spite of solid fusion (Bosworth et al 1955; Laurent and Österman 1976; Boxall et al 1979).

Harrington and Tullos (1971) recommended open reduction maintained by instrumentation. Since then, numerous methods have been reported for the reduction of severe slip (Michel 1971; Inoue and Ozaki 1972; Schöllner 1975; Harrington and Dickson 1976; Scaglietti, Frontino and Bartolozzi 1976; Snijder et al 1976; Louis and Maresca 1977; Ohki et al 1980; O’Brien 1981, Dick 1984; Balderston and Bradford 1985 ; Zielke and Strempel 1986; O’Brien, Mehdian and Jaffray 1988). Several technical problems remain, such as finding a safe and effective method of reduction, and maintaining it until fusion is solid. The rate of major complications is unacceptably high (from $10 \%$ to $60 \%$ ) (McPhee and O'Brien 1979; Boxall et al 1979; Bradford 1979; Sijbrandi 1981). Most series report small numbers of patients, and the follow-up periods are short. The main question, 
however, is whether there is any real indication for the reduction of spondylolisthesis (Nachemson and Wiltse 1976). Johnson and Kirwan (1983) emphasised the safety of fusion in situ, presenting good long-term results in 17 patients.

Our present study aims to evaluate the long-term results of fusion in situ for severe spondylolisthesis in children and adolescents.

\section{PATIENTS AND METHODS}

From 1948 to 1980,93 patients under 20 years of age, with spondylolisthesis of $50 \%$ or more, had operations at the Orthopaedic Hospital of the Invalid Foundation in Helsinki. Eighty-seven of these $(94 \%)$ were re-examined from five to 32 years (mean 13.8 years) after surgery. On average, pre-operative slipping was $76 \%$ (range $50 \%$ to $118 \%$ ), with 45 having more than $75 \%$ and 10 having total spondyloptosis. In all cases there was lysis of the pars interarticularis of the fifth lumbar vertebra.

There were 52 girls $(60 \%)$ and 35 boys. The mean age at the time of operation was 14.8 years (eight to 19 years) and this was lower in girls at the onset of symptoms and at the time of operation. The slipping in girls was also more severe (Table I). All but one of the 10 with spondyloptosis were girls. More than one-third of the patients had dysplastic changes in the facet joints and posterior arch, while $40 \%$ had lumbosacral spina bifida.

The first symptom was low back pain in $50 \%$, pain radiating to the lower extremities in $30 \%$ and merely an abnormal posture in $20 \%$. However, by the time of the operation, $86 \%$ had low back pain, $82 \%$ had radiating pain and $74 \%$ had both. Five patients were asymptomatic prior to the operation. Tightness of the hamstrings (limitation of straight leg raising to less than $60^{\circ}$ ) was seen in half of the patients, 14 had absence of ankle jerk, three had weakness of toe extension, and one girl with total slip had a cauda equina syndrome (Table II). The frequency of low-back and radiating pain pre-operatively was associated significantly with the severity of lumbosacral kyphosis, but not significantly with the severity of slip (Table III).

Operative techniques. All patients had fusion in situ. At the same time, in 23 patients with radicular symptoms, the loose posterior element was removed. Posterior fusion was performed in 54 cases, posterolateral in 30 and anterior in three. Of the posterior fusions, 28 were performed by Albee's technique (1911) and 25 by Hibbs' technique (1911). In 1975 the operative technique was changed to posterolateral fusion. In seven cases the fusion was from the sacrum to L5, in 51 from the sacrum to L4, and in 2! from the sacrum to L3. Postoperative immobilisation in a plaster, corset or brace lasted from eight to 16 weeks.

Follow-up examination. At follow-up patients were evaluated clinically and radiologically. Complete medical records and radiographs were available for all patients.
Table I. Age and radiographic findings pre-operatively and at followup in 87 patients having fusion in situ for severe spondylolisthesis

\begin{tabular}{llll}
\hline & $\begin{array}{l}\text { Girls } \\
(\mathrm{n}=52)\end{array}$ & $\begin{array}{l}\text { Boys } \\
(\mathrm{n}=35)\end{array}$ & $\begin{array}{l}\text { Significance } \\
\text { of difference }\end{array}$ \\
\hline $\begin{array}{l}\text { Pre-operatively } \\
\text { Age at onset of symptoms } \\
\text { years, mean } \pm \text { s.d. }\end{array}$ & $13.2 \pm 2.7$ & $14.3 \pm 2.1$ & $\mathrm{p}<0.05$ \\
$\begin{array}{l}\text { Age at operation } \\
\text { years, mean } \pm \text { s.d. }\end{array}$ & $14.4 \pm 2.4$ & $15.5 \pm 1.7$ & $\mathrm{p}<0.05$ \\
$\begin{array}{l}\text { Slip at diagnosis } \\
\text { per cent, mean } \pm \text { s.d. }\end{array}$ & $74 \pm 19$ & $69 \pm 15$ & $\mathrm{NS}$ \\
$\begin{array}{l}\text { Slip pre-operatively } \\
\text { per cent, mean } \pm \text { s.d. }\end{array}$ & $79 \pm 20$ & $71 \pm 15$ & $\mathrm{p}<0.05$ \\
$\begin{array}{l}\text { Lumbrosacral kyphosis* } \\
\text { degrees, mean } \pm \text { s.d. }\end{array}$ & $29 \pm 17$ & $14 \pm 16$ & $\mathrm{p}<0.001$ \\
$\begin{array}{l}\text { At follow-up } \\
\text { Age } \\
\text { years, mean } \pm \text { s.d. }\end{array}$ & $27.3 \pm 9.6$ & $28.5 \pm 10.9$ & $\mathrm{NS}$ \\
$\begin{array}{l}\text { Slip } \\
\text { per cent, mean } \pm \text { s.d. }\end{array}$ & $81 \pm 23$ & $75 \pm 16$ & $\mathrm{NS}$ \\
$\begin{array}{l}\text { Lumbosacral kyphosis } \\
\text { degrees, mean } \pm \text { s.d. }\end{array}$ & $40 \pm 22$ & $24 \pm 21$ & $\mathrm{p}<0.001$ \\
\hline
\end{tabular}

* sagittal rotation angle

Table II. Symptoms and signs pre-operatively and at followup in 87 patients

\begin{tabular}{lll}
\hline & Pre-operatively & At follow-up \\
\hline Low back pain & 75 & 24 \\
Radiating pain & 70 & 7 \\
Low back and radiating pain & 63 & 7 \\
No pain & 5 & 63 \\
Tight hamstrings* & 45 & 3 \\
Neurological deficit & 14 & 9 \\
\hline
\end{tabular}

- straight leg raising less than $60^{\circ}$

Table III. Association of pre-operative pain to the pre-operative severity of the slip and of the lumbosacral kyphosis

\begin{tabular}{lll}
\hline Pre-operative pain & $\begin{array}{l}\text { Slip (per cent } \\
\text { mean } \pm \text { s.d.) }\end{array}$ & $\begin{array}{l}\text { Lumbosacral kyphosis* } \\
\text { (degrees, mean } \pm \text { s.d.) }\end{array}$ \\
\hline Low back pain (75) & $77 \pm 17$ & $26 \pm 14$ \\
No low back pain (12) & $69 \pm 12$ & $4 \pm 10$ \\
Significance of difference & NS & p $<0.001$ \\
Radiating pain (70) & $77 \pm 18$ & $27 \pm 16$ \\
No radiating pain (17) & $71 \pm 17$ & $7 \pm 11$ \\
Significance of difference & NS & p $<0.001$ \\
\hline
\end{tabular}

* measured as sagittal rotation angle 


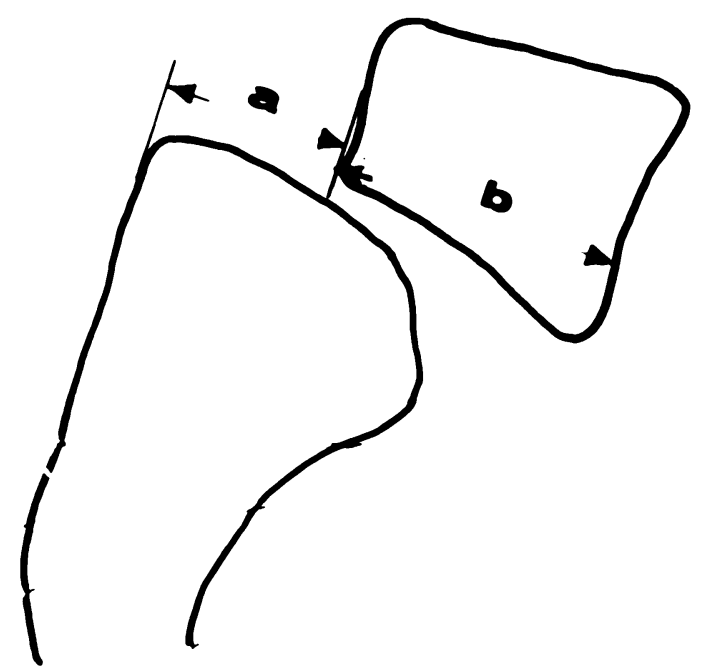

Fig. 1

Anterior slip was measured as a percentage of the width of the listhetic vertebral body $(\mathrm{a} / \mathrm{b} \times 100)$.

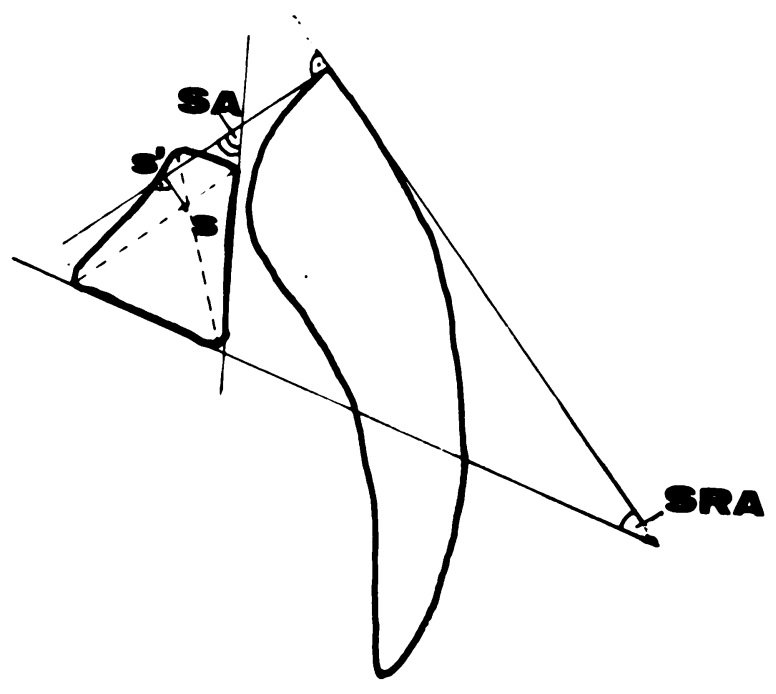

Fig. 2

Lumbosacral kyphosis was measured as the sagittal rotation angle (SRA) and as the slip angle (SA). Sinking of the vertebra was measured as change in the shortest distance from the midpoint of the body of L5 to a line drawn along the top of S perpendicular to its posterior border (S-S').

Table IV. Clinical results at followup, for criteria see text

\begin{tabular}{lccc}
\hline & Female & Male & Total \\
\hline Excellent & 34 & 29 & 63 \\
Good & 4 & 4 & 8 \\
Fair & 12 & 1 & 13 \\
Poor & 2 & 1 & 3 \\
Total & 52 & 35 & 87 \\
\hline
\end{tabular}

A history of pain, physical performance and cosmetic disturbance was taken, and any difficulties during pregnancy and delivery were recorded. The clinical result was related to the severity of complaints: this was graded as excellent if there was no pain; good if there was occasional pain, which did not disturb working or sports activity; fair if there was periodic low-back pain or radiating pain interfering with sports activity or working capacity; and poor if the patient had received a disability pension because of-low back pain or the symptoms were worse than at the initial diagnosis. Every patient scored the severity of pain during sitting, walking, running and lifting as $\mathbf{0}$ for no pain, 1 for moderate pain, and 2 for severe pain. This gave individual total pain scores ranging from 0 to 8 .

Radiographic measurements. Slip was measured according to Laurent and Einola (1961) as a percentage of the width of the olisthetic vertebral body (Fig. 1). The lumbosacral kyphosis was measured both as the sagittal rotation angle (SRA) between a line drawn along the posterior border of the body of $\mathrm{S} 1$ and one drawn along the anterior border of the body of L5 (Wiltse and Winter 1983) (Fig. 2) and as the lumbosacral slip angle (SA). The SA was the angle between a line drawn parallel to the inferior aspect of the body of L5 and a line drawn perpendicular to the posterior aspect of the body of S1 (Fig. 2). Sinking of the olisthetic vertebral body was recorded by measuring the shortest distance from the mid-point of this body to a line drawn along the top of the body of S1 perpendicular to the line of its posterior border (Fig. 2).

Sacroiliac osteoarthritis was diagnosed from the anteroposterior radiographs only when there was a narrowed joint space, irregular joint contours, subchondral sclerosis, and marginal osteophytes (Dihlman 1980). $\mathrm{K}$ issing spines were diagnosed when radiographs showed definite sclerosis between two spinous processes. A semiquantitative assessment of disc height (Saraste et al 1985) was made from the lateral radiographs using four groups; normal, height decreased by less than $50 \%$, decreased by at least $50 \%$, and disc completely eliminated.

Statistical calculations used Student's $t$-test and the chi-square test.

\section{RESULTS}

At follow-up examination the mean age of the patients was 28.6 years (range 21 to 54 years). Of the 87 patients reviewed, $77(89 \%)$ stated that they had been improved by the operation, four $(5 \%)$ were unchanged and one $(1 \%)$ had deteriorated. Five $(6 \%)$ had been asymptomatic preoperatively. The relief of radiating pain had been immediate in 63 of 70 patients $(90 \%)$. Symptoms present at follow-up are shown in Table II. Six patients $(7 \%)$ had taken analgesics during the past year because of back pain and three had disability pensions for their back disorders. 
The clinical results are presented in Table IV. Operative technique made no significant difference to clinical results or pain scores. Neither the postoperative progression of the slip and its severity, nor the amount of lumbosacral kyphosis at follow-up showed statistically significant correlation with the clinical results. Men had a better outcome than women ( $p<0.05)$.

Forty-one patients $(47 \%)$ participated in sports two or more times weekly, which included motocross (motorcycle scrambling), basketball, volleyball, bowls and water polo at national or top competitive levels. Seventeen patients $(20 \%)$ reported that they did not undertake any sports activity. Eight women, all with spondyloptosis, considered their back deformity to be cosmetically disturbing.
During the follow-up period, the female patients had given birth to a total of 35 children. Eight deliveries were performed by Caesarean section, mainly because the olisthesis was documented in the patient's case history, and two had prolonged labour. At follow-up, the true conjugate of the pelvis (symphysis pubis to vertebral column) was measured in six girls with total or subtotal slip: in only one case was this below normal.

Radiological results. Mean values of slip and lumbosacral kyphosis according to sex are given in Table I. Nonunion was found in three patients. Twelve patients $(14 \%)$ fulfilled the radiographic criteria of Dihlman (1980) for definite osteoarthritis of the sacroiliac joints. These patients had a more severe average slip and greater lumbosacral kyphosis than the others (Table V, Fig. 3),

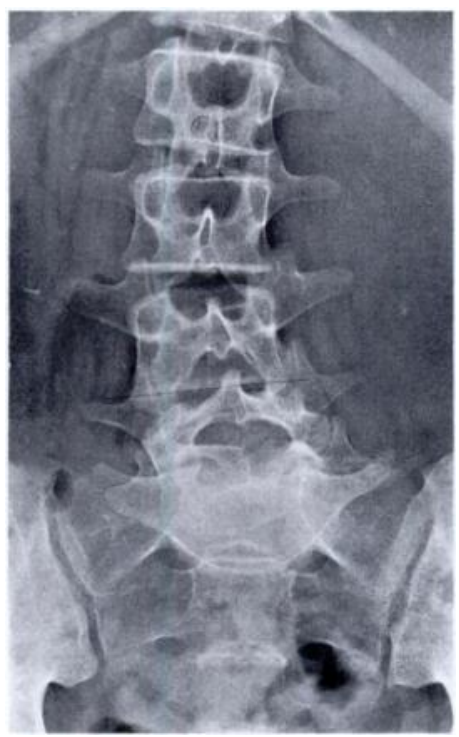

Fig. 3a

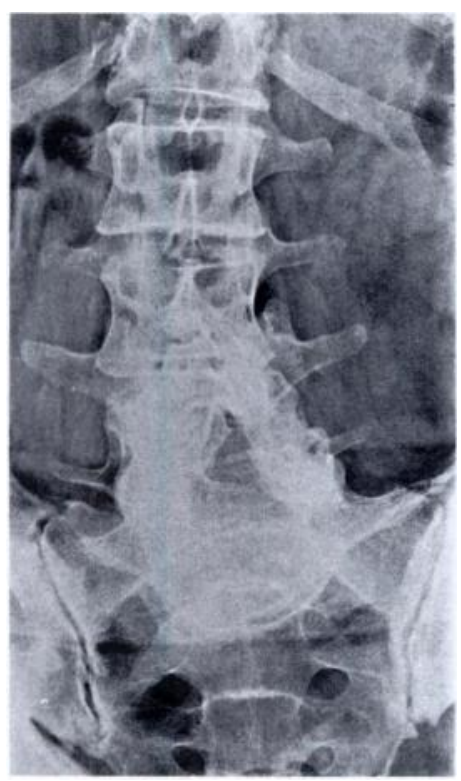

Fig. 3c

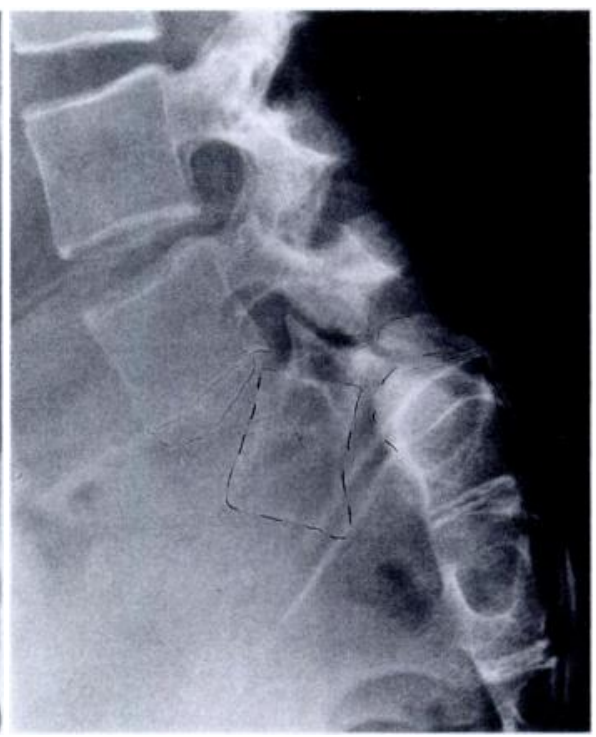

Fig. 3b

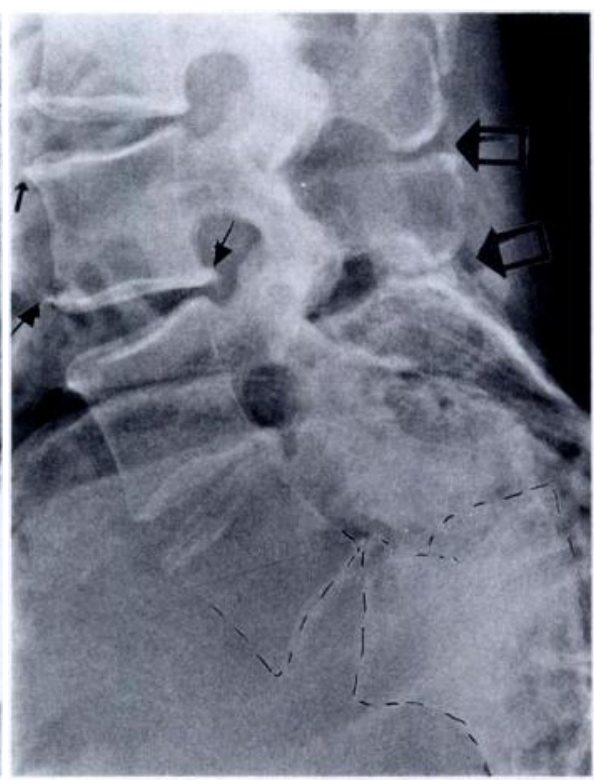

Fig.3d
Figures $3 \mathrm{a}$ and $3 \mathrm{~b}$ - Radiographs of a 16-yearold boy with spondyloptosis of $L 5$.

Figures $3 c$ and $3 d$ - Twenty-five years after removal of the loose posterior arch and posterior fusion from the sacrum to L3. The lumbosacral kyphosis has increased from $54^{\circ}$ to $85^{\circ}$ (sagittal rotation angle) and the vertebral body has sunk $18 \mathrm{~mm}$. Sacroiliac osteoarthritis, kissing spinous processes (arrows), and traction spurs (thin arrows) are seen. 
Table V. Percentage slip and lumbosacral kyphosis in degrees measured as sagittal rotation angle (SRA) and as slip angle (SA) at follow-up in patients with and without radiographic signs of sacroiliac osteoarthritis or of kissing spinous processes (mean \pm s.d.)

\begin{tabular}{|c|c|c|c|}
\hline & $\begin{array}{l}\text { Sacroiliac } \\
\text { osteoarthritis } \\
(n=12)\end{array}$ & $\begin{array}{l}\text { Others } \\
(n=75)\end{array}$ & $\begin{array}{l}\text { Significance } \\
\text { of difference }\end{array}$ \\
\hline Slip & $91 \pm 15$ & $76 \pm 20$ & $\mathrm{p}<0.05$ \\
\hline SRA & $61 \pm 18$ & $29 \pm 22$ & $\mathrm{p}<0.001$ \\
\hline \multirow[t]{2}{*}{ SA } & $80 \pm 26$ & $36 \pm 20$ & $\mathrm{p}<0.001$ \\
\hline & $\begin{array}{l}\text { Kissing spinous } \\
\text { processes }(n=14)\end{array}$ & $(n=73)$ & \\
\hline Slip & $92 \pm 17$ & $76 \pm 20$ & $p<0.05$ \\
\hline SRA & $52 \pm 19$ & $30 \pm 23$ & $p<0.01$ \\
\hline SA & $76 \pm 24$ & $35 \pm 22$ & $\mathrm{p}<0.001$ \\
\hline
\end{tabular}

Table VII. Progression of slip and lumbosacral kyphosis in patients treated by fusion in situ with or without posterior decompression

\begin{tabular}{|c|c|c|c|}
\hline & \multicolumn{2}{|c|}{$\begin{array}{l}\text { Posterior } \\
\text { decompression }\end{array}$} & \multirow[b]{2}{*}{$\begin{array}{l}\text { Significance } \\
\text { of difference }\end{array}$} \\
\hline & $\begin{array}{l}\text { Yes } \\
(n=23)\end{array}$ & $\begin{array}{l}\text { No } \\
(n=64)\end{array}$ & \\
\hline \multicolumn{4}{|l|}{ Slip } \\
\hline $\begin{array}{l}\text { Pre-operative } \\
\text { (per cent, mean } \pm \text { s.d.) }\end{array}$ & $78 \pm 18$ & $75 \pm 19$ & NS \\
\hline $\begin{array}{l}\text { Progression } \\
\text { (per cent, mean } \pm \text { s.d.) }\end{array}$ & $10 \pm 11$ & $-1 \pm 11$ & $\mathrm{p}<0.01$ \\
\hline \multicolumn{4}{|l|}{ Lumbosacral kyphosis } \\
\hline $\begin{array}{l}\text { Pre-operative } \\
\text { (degrees, mean } \pm \text { s.d.) }\end{array}$ & $28 \pm 18$ & $21 \pm 17$ & NS \\
\hline $\begin{array}{l}\text { Progression } \\
\text { (degrees, mean } \pm \text { s.d.) }\end{array}$ & $19 \pm 12$ & $8 \pm 11$ & $\mathrm{p}<0.01$ \\
\hline
\end{tabular}

Table VI. Number with postoperative progression or correction of the slip or lumbosacral kyphosis of $>10 \%$ (measured as sagittal rotation angle (SRA)) or slip angle (SA) and sinking of the vertebra

\begin{tabular}{lll}
\hline & Progression & Correction \\
\hline Slip $10 \%$ & 19 & 10 \\
SRA $>10$ & 39 & 2 \\
SA $>10$ & 50 & 1 \\
Sinking $>5 \mathrm{~mm}$ & 44 & - \\
\hline
\end{tabular}

but did not have significantly different symptoms from the rest of the series at follow-up.

Kissing spinous processes, with sclerosis between them, were seen in 14 patients, all of whom had some back pain provoked by hyperextension (Fig. 3). They also showed more severe slipping, and a greater lumbosacral kyphosis than the others (Table V).

Seven patients $(8 \%)$ had fusion at one level only (three anterior and four posterolateral fusions). At followup they all had marked degeneration of the $\mathrm{L} 4 / 5$ disc above the fusion (more than $50 \%$ reduction of height). These patients had significantly more clinical symptoms than the others; six of the seven had a fair or poor clinical result as against 10 of the other $80(\mathrm{p}<0.001)$.

Progression of the deformity. The mean slip at follow-up was $78 \%$, that is $2 \%$ more than pre-operatively; $19(22 \%)$ showed progression of more than $10 \%$, but $10(11 \%)$ had correction by more than $10 \%$, most in association with vertebral remodelling (Table VI) (Fig. 4).

Further rotation of the spondylolisthetic vertebra, or progression of the lumbosacral kyphosis, measured as an increase of more than $10^{\circ}$ in the sagittal rotation angle,

Figure $4 \mathrm{a}$ - Lateral radiograph of a 13-yearold girl with a $60 \%$ slip before operation. Figure $4 b$ - Eleven years after posterior fusion from the sacrum to L4. There has been remodelling during the growth period.

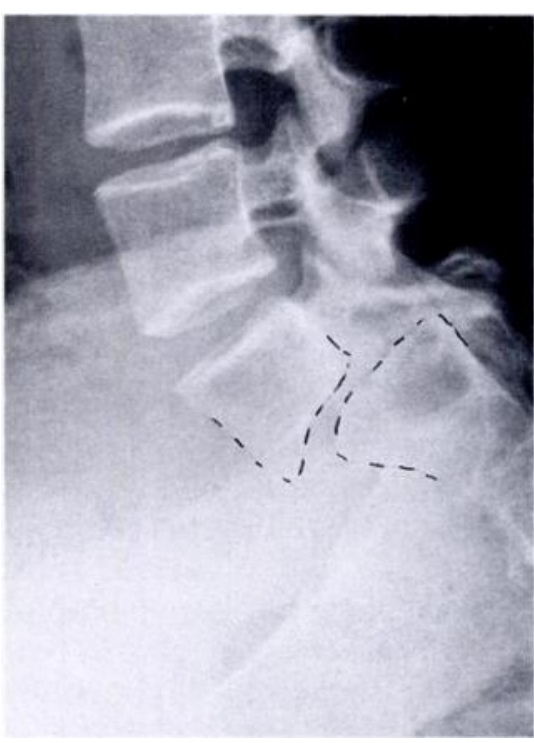

Fig. 4a

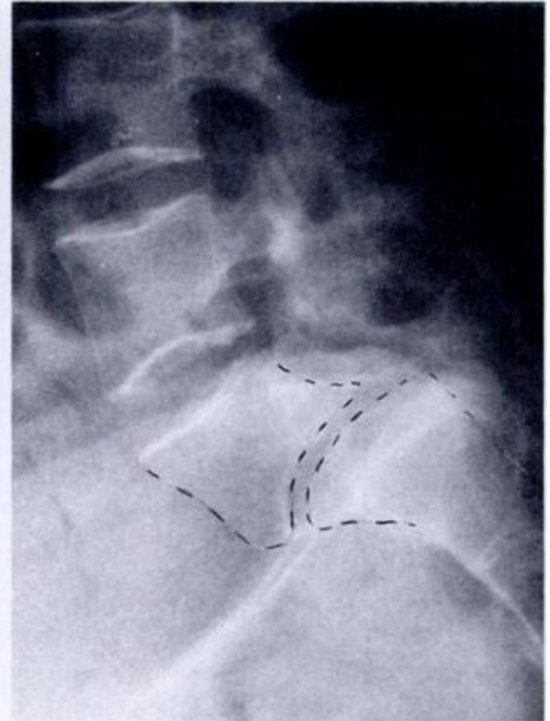

Fig. $4 b$ 
was found in $45 \%$ and progression of the slip angle by more than $10^{\circ}$ in $57 \%$. In 44 severe cases caudal sinking of the vertebra by more than $5 \mathrm{~mm}$ occurred during the follow-up (Table VI). Patients showing progression of the slip had no more re-operations or non-unions than the others.

The patients who had removal of the posterior element at the time of fusion had a greater progression of the slip and lumbosacral kyphosis postoperatively than those without decompression ( $\mathrm{p}<0.001$ ) (Table VII). By contrast, we found no statistical correlation between the fusion technique (posterior or posterolateral), the extent of fusion, or the type of bone graft and any measure of progression.

Postoperative complications. Eight patients $(9 \%)$ had early complications, four with superficial wound infection, three with transient extensor palsy of the great toe, and one with a fracture of the tibia at the donor site. The one patient with cauda equina symptoms pre-operatively had good pain relief, but sphincter function recovered only partially.

Eleven patients $(13 \%)$ had a re-operation for nonunion and five $(6 \%)$ required decompression later for root compression symptoms. These re-operations took place a mean of 25 months after the original fusion.

\section{DISCUSSION}

Most series which report the long-term follow-up of children and adolescents after operation for severe spondylolisthesis are small (Snijder et al 1976; Boxall et al 1979; Bradford 1979; McPhee and O'Brien 1979; Verbiest 1979; DeWald et al 1981; Suezawa, Jacob and Katada 1983; Matthiass and Heine 1986). Johnson and Kirwan (1983) reported good results from fusion in situ with insignificant pain and no pseudarthroses in 17 patients. Only two of their patients $(12 \%)$ considered that their spine deformity was cosmetically disturbing.

We now report 87 patients with severe spondylolisthesis treated by fusion in situ during childhood or adolescence. In general, the long-term clinical results and the patient's assessments were good. The patients with severe radicular symptoms and low-back pain had relief soon after the operation. On average the slip had progressed from $76 \%$ to $78 \%$ during follow-up, but this represented a wide scatter in progression and correction. Correction of more than $10 \%$ (up to $30 \%$ ) was seen in 10 patients. All of these had their in situ fusion at 10 to 14 years of age, and all had increased in height by more than $6 \mathrm{~cm}$ during follow-up. It seems that corrective remodelling occurs during growth in patients operated on at an early age.

In severe displacement, considerable slipping has already taken place, and the measurement of its increase does not fully describe any changes. It is therefore necessary to review changes in the sagittal rotation of the slipped vertebra as an indicator of lumbosacral kyphosis.
Wiltse and Winter (1983) suggested the sagittal rotation angle (SRA) (Fig. 2) while Bradford (1979) measured the slip angle (SA) (Fig. 2). Using the SRA, we found further rotation of over $10^{\circ}$ in 39 patients $(45 \%)$. On the same radiographs, the slip angle showed an increase of over $10^{\circ}$ postoperatively in 50 patients $(57 \%)$ (Table VI). We feel that the SA in severe cases gives erroneously high rates of kyphosis because of the progressive deformity of the caudal end-plate by wedging of the slipped vertebra. The SRA therefore appears to be a more reliable measure of progression. For the same reason, the method of Laurent and Einola (1961) for measurement of percentage slip, seems more reliable than the original method by Taillard (1954), because of the major deformation and rounding of the cranial aspect of the sacrum in cases with severe slip.

In addition to slip and kyphotic angulation the L5 vertebra may also sink caudally. Dandy and Shannon (1971) divided the upper plate and the anterior border of the first sacral vertebra into five equal parts to include this factor, but we used the shortest distance of the midpoint of the body of L5 to the plane of the upper edge of S1 (Fig. 2). At follow-up we found sinking of more than $5 \mathrm{~mm}$ ( 6 to $25 \mathrm{~mm}$ ) in 44 patients $(50 \%)$, but these values include, of course, the sinking caused by disc degeneration.

It appears, as shown earlier, that it is not possible to prevent the progression of severe spondylolisthesis by posterior or posterolateral fusion (Laurent and Österman 1976; Suezawa and Walker 1978). Attempted fusion by the posterior technique might even accelerate progression at first, because of damage to the posterior stabilising structures caused by the operation itself. (Suezawa, Bernoski and Jacob 1981). Our observations support this idea, since more progression of slip and lumbosacral kyphosis was found after fusion and posterior decompression than after posterior fusion alone.

There is some evidence that severe lumbosacral kyphosis with secondary lumbar lordosis has a harmful influence on structures other than the olisthetic segment itself. We found more disc degeneration and worse clinical results where only one segment had been fused, and do not recommend this in cases with a severe slip. Kissing spinous processes with back pain symptoms, and osteoarthritic changes in sacroiliac joints were also typically found in patients with the most severe slip. The causes may be increased shearing load on discs and sacroiliac joints.

Fusion in situ is a safe method. There are few complications and the long-term results are acceptable though the natural history of untreated severe spondylolisthesis is not fully known. In our series, the pre-operative symptoms were extremely severe, and the fact that radicular symptoms were cured by fusion speaks for surgical treatment.

However, posterior techniques cannot prevent progression of severe slips, and increase of lumbosacral 
kyphosis seems to cause problems even outside the area of fusion. To prevent these secondary changes, operative reduction of lumbosacral kyphosis may be indicated in such cases. It may be that new developments in instrumentation, such as transpedicular fixation, will make it possible to achieve and maintain an adequate correction.

No benefits in any form have been received or will be received from a commercial party related directly or indirectly to the subject of this article.

\section{REFERENCES}

Albee FH. Transplantation of a portion of the tibia into the spine for Pott's disease : a preliminary report. JAMA 1911; $57: 885$.

Balderston RA, Bradford DS. Technique for achievement and maintenance of reduction for severe spondylolisthesis using spinous process traction wiring and external fixation of pelvis. Spine 1985 10:376-82

Bosworth DM, Fielding JW, Demarest L, Bonaquist M. Spondylolisthesis: a critical review of a consecutive series of cases treated by arthrodesis. J Bone Joint Surg [Am] 1955; 37-A :767-86.

Boxall D, Bradford DS, Winter RB, Moe JH. Management of severe spondylolisthesis in children and adolescents. J Bone Joint Surg [Am] 1979; 61-A :479-95.

Bradford DS. Treatment of severe spondylolisthesis: a combined approach for reduction and stabilisation. Spine 1979; 4:423-9.

Dandy DJ, Shannon MJ. Lumbo-sacral subluxation (Group 1 spondylolisthesis). J Bone Joint Surg [ Br] 1971 ; 53-B :578-95.

DeWald RL, Faut MM, Taddonio RF, Neuwirth MG. Severe lumbosacral spondylolisthesis in adolescents and children: reduction and staged circumferential fusion. J Bone Joint Surg [Am] 1981; 63A:619-26.

Dick W. Innere Fixation von Brust - und Lendenwirbel-frakturen. Aktuelle Probleme in Chirurgie und Orthopädie 28. Bern, etc: Verlag Hans Huber 1984.

Dihlmann NW. Diagnostic radiology of the sacroiliac joints. Stuttgart, etc: Georg Thieme Verlag, 1980

Harrington PR, Tullos HS. Spondylolisthesis in young patients: observations and surgical treatment. Clin Orthop 1971;79:75-84.

Harrington PR, Dickson JH. Spinal instrumentation in the treatment of severe progressive spondylolisthesis. Clin Orthop 1976; 117 157-63.

Hibbs RA. An operation of progressive spinal deformities. The preliminary report of 3 cases. New York Med J 1911; 93:1013.

Inoue S, Ozaki K. Anterior fusion for spondylolysis and spondylolisthesis. Saigai-Igaku 1972; 15:919-34.

Johnson JR, Kirwan EO'G. The long-term results of fusion in situ for severe spondylolisthesis. J Bone Joint Surg [Br] 1983; 65-B :43-6.

Jenkins JA. Spondylolisthesis. Br J Surg 1936; 24 :80-5.

Laurent LE, Einola S. Spondylolisthesis in children and adolescents. Acta Orthop Scand 1961; $31: 45-64$.

Laurent LE, Österman K. Operative treatment of spondylolisthesis in young patients. Clin Orthop 1976; 117:85-91
Louis R, Maresca C. Stabilisation chirurgicale avec réduction des spondylolyses et des spondylolisthésis. Int Orthop 1977; $1: 215-25$.

Matthiass HH, Heine $\mathbf{J}$. The surgical reduction of spondylolisthesis. Clin Orthop 1986; 203:34-44.

McPhee IB, O'Brien JP. Reduction of severe spondylolisthesis: a preliminary report. Spine $1979 ; 4: 430-4$

Meyerding HW. Spondylolisthesis. Surg Gynecol Obstet 1932; 54: 371-7.

Michel C-R. Réduction et fixation des spondylolisthesis et des spondyloptoses. Rev Chir Orthop 1971 ; 57 Suppl I :148-57.

Nachemson A, Wiltse LL. Editorial comment: spondylolisthesis. Clin Orthop 1976; 117:2-3.

Newman PH, Stone KH. The etiology of spondylolisthesis. J Bone Joint Surg [Br] 1963; 45-B:39-59.

O'Brien JP, Mehdian H, Jafiray D. Reduction of severe lumbosacral spondylolisthesis: a report of 22 cases with follow-up from 4-12 years. Abstracts of meeting in Miami April 1988. Toronto: International Society for the Study of the Lumbar Spine:25.

O'Brien JP. Severe spondylolisthesis. Sicot 15th World Congress, $1981: 138$.

Ohki I, Inowe S, Murata T, Mikanagi K, Shibuya K. Reduction and fusion of severe spondylolisthesis using halo-pelvic traction with a wire reduction device. Int Orthop 1980; 4:107-13.

Saraste H, Broström LA, Aparisi T, Axdorph G. Radiographic measurement of the lumbar spine: a clinical and experimental study in man. Spine 1985; 10:236-41.

Scaglietti O, Frontino G, Bartolozxi P. Technique of anatomical reduction of lumbar spondylolisthesis and its surgical stabilization Clin Orthop 1976; 117:164-75.

Schöllner D. Ein neues Verfahren zur Reposition und Fixation bei Spondylolisthesis. Orthop Praxis 1975; $11: 270-4$.

Sijbrandij S. A new technique for the reduction and stabilisation of severe spondylolisthesis. J Bone Joint Surg [Br] 1981; 63-B: 266-71.

Snijder JGN, Seroo JM, Snijder CJ, Schijvens AWM. Therapy of spondylolisthesis by repositioning and fixation of the olisthetic vertebra. Clin Orthop 1976; 117:149-5.

Suezawa Y, Walker N. Progredientes Wirbelgleiten bei schwerer Spondylolisthesis. Z Orthop 1978; 116:325-30. (Eng. abstr.)

Suezawa Y, Jacob HA, Katada S. Indikation zur operativen Korrektur der schweren Spondylolisthesis und Beeinflussung der lumbalen Fehlhaltung. Z Orthop 1983; 121 :555-63. (Eng. abstr.)

Suezawa Y, Bernoski FP, Jacob HAC. A comparison of the long term results of three types of posterior fusion of the lumbar spine for spondylolisthesis. Int Orthop 1981 ; 5:291-7.

Taillard W. Le spondylolisthesis chez l'enfant et l'adolescent : (etude de 50 cas). Acta Orthop Scand 1954; 24:115-24

Turner RH, Bianco AJ Jr. Spondlolysis and spondylolisthesis in children and teen-agers. J Bone Joint Surg [ Am] 1971; 53-A :1298-306.

Verbiest $\mathbf{H}$. The treatment of lumbar spondyloptosis or impending lumbar spondyloptosis accompanied by neurologic deficit and/or neurogenic intermittent claudication. Spine 1979; 4:68-77.

Watkins MB. Posterolateral fusion of the lumbar and lumbosacral spine. J Bone Joint Surg [Am] 1953; 35-A:1014-8.

Wiltse LL. Spondylolisthesis in children. Clin Orthop $1961 ; 21: 156-63$.

Wiltse LL, Winter RB. Terminology and measurements of spondylolisthesis. J Bone Joint Surg [Br] 1983; 65-A:768-72.

Zielke K, Strempel AV. Posterior lateral distraction spondylodesis using twofold sacral bar. Clin Orthop 1986; 203:151-8. 